\title{
Crescimento, produção de biomassa e eficiência fotossintética da bananeira sob fertirrigação com nitrogênio e potássio ${ }^{1}$
}

\author{
Growth, biomass yield and photosynthetic efficiency of banana, under fertirrigation \\ with nitrogen and potassium
}

\author{
Alberto Soares de Melo ${ }^{2 *}$, Pedro Dantas Fernandes ${ }^{3}$, Lafayette Franco Sobral ${ }^{4}$, Marcos Eric Barbosa Brito ${ }^{3}$ e \\ Jolly Dayanne Melo Dantas ${ }^{5}$
}

\begin{abstract}
Resumo - O objetivo do trabalho foi avaliar os efeitos de doses de nitrogênio e de potássio fornecidos via água de irrigação, nas características morfofisiológicas da bananeira, cultivar 'Prata-Anã', em solo dos tabuleiros costeiros do estado de Sergipe. O experimento foi realizado em campo, utilizando o fatorial $4 \times 4$ com quatro blocos casualizados, na Estação Experimental da Universidade Federal de Sergipe. Foram avaliados os efeitos das doses de nitrogênio aos níveis de 0; 250; 500 e $750 \mathrm{~kg} \mathrm{ha-1} \mathrm{na}^{-1}$ forma de uréia e $\mathrm{K}_{2} \mathrm{O}$ nos valores de $0 ; 290 ; 580$ e $870 \mathrm{~kg} \mathrm{ha}^{-1}$ oriundo do cloreto de potássio. Foram coletados dados referentes ao crescimento vegetativo, partição de fitomassa seca e eficiência fotossintética das plantas. O maior ganho na produção de fitomassa seca da parte aérea $\left(8054,88 \mathrm{~g}_{\text {planta }}{ }^{-1}\right)$ correspondeu ao tratamento $700 \mathrm{~kg} \mathrm{ha}^{-1}$ ano $^{-1} \mathrm{de} \mathrm{N} \mathrm{e} 1200 \mathrm{~kg} \mathrm{ha}^{-1} \mathrm{ano}^{-1} \mathrm{de}$ $\mathrm{K}_{2} \mathrm{O}$, sendo $16,51 \%$ destinados à fitomassa seca das folhas, $43,77 \%$ à fitomassa seca do pseudocaule e $39,71 \%$ à fitomassa seca do cacho. Doses elevadas de $\mathrm{N}$ e baixas de $\mathrm{K}$ causam a ontogenia mais rápida das folhas, diminuindo a razão da área foliar com reflexos negativos no rendimento da cultura. A maior conversão da irradiação solar em fitomassa seca pela bananeira foi obtida no tratamento com $732 \mathrm{~kg} \mathrm{ha}^{-1}$ de $\mathrm{N}$ e $1200 \mathrm{~kg} \mathrm{ha}^{-1}$ de $\mathrm{K}_{2} \mathrm{O}$.
\end{abstract}

Palavras-chave - Plantas-nutrição. Plantas-efeito do potássio. Plantas-efeito do nitrogênio. Biomassa vegetal.

\begin{abstract}
The objective of this study was to evaluate effects of nitrogen and potassium applied trough water irrigation on physiological characteristcs of banana cv Prata Anã in the coastal tablelands of Sergipe State. The experiment was carried out in the Sergipe Federal University Experiment Station, as 4x4 factorial, in randomized blocks with four repplications. Doses of nitrogen as ureia were $\left(0 ; 250 ; 500 \mathrm{e} 750 \mathrm{~kg} \mathrm{ha}^{-1}\right)$ and doses of potassium as potassium chloride were $(0 ; 290 ; 580$ e 870, in $\mathrm{kg} \mathrm{ha}^{-1}$ of $\mathrm{K}_{2} \mathrm{O}$ ). Vegetative growth, biomass partition and photosynthesis efficiency were determined. Plant aerial biomass of $8054.88 \mathrm{~g}$ plant $^{-1}$ was achieved with the application of $700 \mathrm{~kg} \mathrm{ha}^{-1}$ year $^{-1}$ of $\mathrm{N}$ and $1200 \mathrm{~kg} \mathrm{ha}^{-1}$ year $^{-1}$ of $_{2} \mathrm{O}$. Biomass distribution was: 16.515 to the leaves, $43.77 \%$ to the stem and $39.71 \%$ to fruit brunches. Higher nitrogen and low potassium causes ontogeny, decreasing leaf area index and yield. Maximum solar irradiation conversion into biomass was observed at $732 \mathrm{~kg} \mathrm{ha}^{-1}$ of $\mathrm{N}$ e $1200 \mathrm{~kg} \mathrm{ha}^{-1}$ of $\mathrm{K}_{2} \mathrm{O}$.
\end{abstract}

Key words - Plant nutrition. Plant-effect of potassium. Plant-effect of nitrogen. Plant biomass.

\footnotetext{
* Autor para correspondência

${ }^{1}$ Recebido para publicação em 21/05/2009; aprovado em 05/07/2010

Parte da Tese de Doutorado do primeiro autor apresentada no Programa de Pós-Graduação em Recursos Naturais da Universidade Federal de Campina Grande

${ }^{2}$ Departamento de Agrárias e Exatas, Campus IV da Universidade Estadual da Paraíba, Sítio Cajueiro, Catolé do Rocha-PB, Brasil, 58.884-000, alberto@uepb.edu.br

${ }^{3}$ Departamento de Engenharia Agrícola, CTRN/UFCG, Avenida Aprígio Veloso, 882, Campina Grande-PB, Brasil, 58.109-850, pdantas@pq.cnpq.br, mebbrito@yahoo.com.br

${ }^{4}$ Embrapa Tabuleiros Costeiros, Avenida Beira Mar, 1150, Aracaju-SE, Brasil, 49.000-000, lafayete@cpatc.embrapa.br

${ }_{5}^{5}$ Departamento de Engenharia Agronômica da Universidade Federal de Sergipe, São Cristóvão-SE, Brasil, 49.000-100, pviegas@ufs.br
} 


\section{Introdução}

A bananeira (Musa spp) é uma das fruteiras mais exploradas e seu fruto um dos mais consumidos no mundo, sendo o Brasil o segundo maior produtor mundial, com 6,8 milhões de toneladas, e o maior consumidor. Essa fruta é o $13^{\circ}$ produto agrícola nacional, com área plantada de $495 \mathrm{mil} \mathrm{ha}$, situando-se em $2^{\circ}$ lugar entre as frutas, sendo inferior apenas à produção da laranja (FAO, 2007). As transações internacionais da banana atingiram 14,7 milhões de toneladas e o Brasil foi responsável por 241 mil toneladas, no ano de 2002; em 2005 as exportações foram de 212 mil toneladas (FAO, 2007), indicando um declínio de 12,03\% no valor comercializado.

A bananeira conforme Borges et al. (2002), Romero; Zamora (2006) é muito exigente em nutrientes durante o período juvenil até o lançamento do cacho, com elevada absorção de K, N, Ca, P e Mg. Dentre os macronutrientes, o potássio e o nitrogênio estão mais diretamente relacionados com o desenvolvimento vegetativo, produção e qualidade dos frutos, variando a quantidade extraída em função da espécie e/ou da cultivar, do metabolismo, do estádio fenológico e da idade das plantas (ROMERO; ZAMORA, 2006). O nitrogênio é o nutriente de maior expressividade do início da emissão das folhas até a emissão da inflorescência, que ocorre entre o $7^{\circ}$ e $10^{\circ}$ mês após plantio; a partir desse período há havendo redução na absorção até a colheita (BORGES et al., 2002). Os autores expressam também que durante o crescimento vegetativo a omissão desse macronutriente compromete o rendimento da cultura, devido o meristema está em pleno desenvolvimento. Quanto ao potássio, ele é considerado um dos elementos mais importante para a cultura da banana (BORGES et al., 2002; MELO et al., 2006), porque atua como ativador enzimático e participa de processos como abertura e fechamento dos estômatos, fotossíntese, transporte de carboidratos e respiração (SHIMAZAKI et al., 2007). Além dessas funções, especificamente na bananeira, participa do balanço de água na planta, na produção de cachos, de pencas e na qualidade dos frutos.

$\mathrm{Na}$ literatura há informações que expressam a nutrição mineral da bananeira sob vários sistemas de cultivo (BORGES et al., 2002; BORGES et al., 2006; DAMATTO JÚNIOR et al., 2006; GUERRA et al., 2004; MAHALAKSHMI et al., 2003; PINTO et al., 2005). Entretanto, as informações científicas disponíveis referentes à aplicação de $\mathrm{N}$ e $\mathrm{K}$ via água de irrigação sobre o comportamento morfofisiológico e a conversão de irradiação solar em biomassa do cultivo da bananeira irrigada, são ainda pouco frequentes.
Nesse sentido, o trabalho teve como objetivo avaliar os efeitos da combinação de doses de nitrogênio e potássio, via água de irrigação, sobre o crescimento vegetativo, partição de biomassa e eficiência fotossintética da bananeira "Prata-Anã", em solo dos tabuleiros costeiros do estado de Sergipe.

\section{Material e métodos}

O trabalho foi realizado no Campus Experimental da Universidade Federal de Sergipe, localizado no município de São Cristóvão (SE), nos tabuleiros costeiros, situado pelos pontos das coordenadas geográficas: latitude $10^{\circ} 19^{\prime} \mathrm{S}$; longitude 36³9' $\mathrm{O}$ de Greenwich, $20 \mathrm{~m}$ acima do nível médio do mar.

A região possui clima, de acordo com a classificação de Köppen, do tipo As', Tropical chuvoso com verão seco e pluviometria em torno de $1200 \mathrm{~mm}$ anuais, com chuvas concentradas nos meses de abril a setembro. O solo da área experimental foi classificado como ARGISSOLO VERMELHO AMARELO Distrófico textura franco-arenosa (SANTOS et al., 2006), e possui os atributos físico-químicos: $\mathrm{pH}=5,2$; $\mathrm{P}=2,4 \mathrm{mg} \mathrm{dm}^{-3} ; \mathrm{K}=0,8 \mathrm{mmol}_{\mathrm{c}} \mathrm{dm}^{-3} ; \mathrm{Ca}^{2+}=5,0 \mathrm{mmol}_{\mathrm{c}} \mathrm{dm}^{-3}$; $\mathrm{Mg}^{2+}=3,9 \mathrm{mmol}_{\mathrm{c}} \mathrm{dm}^{-3} ; \mathrm{Al}^{3+}=2 \mathrm{mmol}_{\mathrm{c}} \mathrm{dm}^{-3} ; \mathrm{H}+\mathrm{Al}^{3+}=25,6$ $\mathrm{mmol}_{\mathrm{c}} \mathrm{dm}^{-3} ; \mathrm{Na}^{+}=0,55 \mathrm{mmol}_{\mathrm{c}} \mathrm{dm}^{-3} ; \mathrm{CTC}=44,5 \mathrm{mmol}_{\mathrm{c}} \mathrm{dm}^{-3}$; $\mathrm{V}=42,47 \%$; M.O = 2,1 dag dm${ }^{-3}$; areia, $632 \mathrm{~g} \mathrm{~kg}^{-1}$ silte, 296 $\mathrm{g} \mathrm{kg}^{-1}$ e argila $72 \mathrm{~g} \mathrm{~kg}^{-1}$, densidade do solo de $1,59 \mathrm{~kg} \mathrm{dm}^{-3}$; capacidade de campo determinada in situ $=0,199 \mathrm{~m}^{3} \mathrm{~m}^{-3} \mathrm{e}$ ponto de murcha $(1500 \mathrm{kPa})=0,033 \mathrm{~m}^{3} \mathrm{~m}^{-3}$.

Foram testados dois fatores: nitrogênio $(0 ; 250$; 500 e $750, \mathrm{~kg} \mathrm{ha}^{-1}$ de $\mathrm{N}$, na forma de uréia) e potássio (0; 290; 580 e $870 \mathrm{~kg} \mathrm{ha}^{-1}$ de $\mathrm{K}_{2} \mathrm{O}$, oriundo do cloreto de potássio) aplicados via fertirrigação durante o primeiro ciclo da bananeira cultivar Prata-Anã, no delineamento de blocos ao acaso em esquema fatorial $4 \times 4$ com quatro repetições, numa área de 1,2 ha e densidade de plantio de 2.400 plantas ha $^{-1}$. Cada parcela foi constituída de 32 plantas, quatro fileiras de 8 plantas, para avaliação das oito plantas centrais.

O solo da área foi submetido a uma aração seguida de uma gradagem para incorporação de $2,5 \mathrm{t} \mathrm{ha}^{-1}$ de calcário $(\mathrm{PRNT}=65 \%)$ a $20 \mathrm{~cm}$ de profundidade, 60 dias antes do plantio. O cálculo do corretivo foi baseado na análise química do solo, de modo elevar a saturação por bases para 70\% (RAIJ et al., 1996). Posteriormente, foi feito coveamento tratorizado por meio de broca helicoidal com $0,50 \mathrm{~m}$ de diâmetro e $0,5 \mathrm{~m}$ de profundidade, de modo romper a camada de impedimento à $0,3 \mathrm{~m}$ de profundidade. A adubação de fundação correspondeu a $300 \mathrm{~g}$ de superfosfato simples $\left(18 \% \mathrm{P}_{2} \mathrm{O}_{5}\right), 60 \mathrm{~g}$ de micronutrientes 
na forma de FTE-BR12 (9\% Zn; 1,8\% B; $0.85 \% \mathrm{Cu} ; 3 \% \mathrm{Fe}$; $2,1 \% \mathrm{Mn}$ e $0,10 \% \mathrm{Mo}), 200 \mathrm{~g}$ de calcário dolomítico e 10 litros de esterco bovino incorporados ao solo 45 dias antes do plantio, em seguida foi realizada uma irrigação prévia. O plantio foi realizado em fileira dupla no espaçamento de 3,00 m x 2,0 m x 2,0 m utilizando mudas micropropagadas adquiridas na Embrapa Mandioca e Fruticultura, depois se realizou a irrigação por microaspersão de modo a manter o solo com umidade próximo à capacidade de campo. As fertirrigações foram aplicadas em frequência quinzenal usando injetor do tipo Venturi com vazão calculada de $100 \mathrm{~L} \mathrm{~h}^{-1}$, ao longo do ciclo fenológico da cultura.

O bananal foi irrigado por meio de um sistema de microaspersão autocompensante com vazão nominal de $1,94 \times 10^{-5} \mathrm{~m}^{3} \mathrm{~s}^{-1}\left(70 \mathrm{~L} \mathrm{~h}^{-1}\right)$, pressão de serviço de $200 \mathrm{kPa}$ e raio de alcance de $2,5 \mathrm{~m}$. A aplicação da água e o manejo da irrigação foram realizados com base no monitoramento climático (COELHO et al., 2000), sendo a evapotranspiração de referência calculada pelo modelo de Penman-Monteith padronizado por Allen et al. (1998). As variáveis meteorológicas foram obtidas por meio de uma estação agrometeorológica automatizada METOS instalada próxima ao experimento. O coeficiente de cultura $(\mathrm{Kc})$ foi obtido com base em Coelho et al. (2000).

$\mathrm{Na}$ avaliação do crescimento das plantas, foram realizadas medições periódicas, iniciadas trinta dias após o transplantio (30 DAT), até a emissão da inflorescência. Contudo, a fitomassa seca da parte aérea (fitomassa das folhas + fitomassa do pseudocaule + fitomassa do cacho) foi quantificada no momento da colheita. Para o pseudocaule, foram utilizadas amostras de $20 \mathrm{~cm}$ de comprimento extraídas da base, do meio e do ápice. Posteriormente, o material vegetal foi colocado estufa a $65{ }^{\circ} \mathrm{C}$, na até biomassa constante, para determinação da fitomassa seca. A área foliar (AF) foi calculada conforme relação proposta por Moreira (1999). Na determinação da área foliar específica (AFE) foram utilizadas amostras de 20 discos extraídos da parte central do limbo foliar, utilizando-se vazador de $0,9 \mathrm{~cm}$ de diâmetro. Posteriormente, os discos foram colocados para secar em estufa com circulação de ar à $65^{\circ} \mathrm{C}$ até massa constante, para obtenção da fitomassa seca.

A eficiência fotossintética $(\xi)$ foi quantificada pela expressão proposta por Figueiredo et al. (2005) e Fonseca et al. (2006). A radiação fotossinteticamente ativa (RFA) foi calculada utilizando os valores da irradiação solar global (Rs) incidente, durante o período de cultivo, corrigidos pelo fator de correção ( $p=0,5)$ (PEREIRA et al. 2002). Os dados da Rs foram coletados na estação Agrometeorológica automatizada próxima à área experimental.

Os dados das variáveis respostas foram submetidos à análise de variância pelo teste $\mathrm{F}$ até $5 \%$ de significância, e os respectivos modelos de regressão foram ajustados de acordo com o coeficiente de determinação até $5 \%$ de significância. Em seguida, as variáveis foram relacionadas por meio de correlação linear de Pearson, sendo utilizados os programas SAEG 9.0 e Table Curve 2D e 3D Jandel.

\section{Resultados e discussão}

As plantas de bananeiras aos 180 dias após transplantio (DAT) apresentaram respostas positivas às doses crescentes de nitrogênio e potássio (FIG. 1a). Analisando o efeito isolado de $\mathrm{N}$, a altura máxima alcançada aos 180 DAT foi de $117,93 \mathrm{~cm}$ na dose de $359,54 \mathrm{~kg} \mathrm{ha}^{-1}$. Comparando o valor de 74,56 cm das plantas que não receberam adubações nitrogenadas e potássicas com o máximo estimado de $\mathrm{N}$, se obteve incremento de 58,17\%. Quanto à ação do potássio as plantas cresceram de forma quadrática atingindo a altura máxima de $86,06 \mathrm{~cm}$ na dose máxima estimada de $304,26 \mathrm{~kg} \mathrm{ha}^{-1}$ de $\mathrm{K}_{2} 0$, resultando num ganho de $15,46 \%$ em relação às plantas dos tratamentos sem nitrogênio e potássio. Houve efeito significativo da interação $\mathrm{N}$ x K e por meio da derivada parcial, obteve-se altura máxima de $134,11 \mathrm{~cm}$ na combinação de $380 \mathrm{~kg} \mathrm{ha}^{-1}$ de $\mathrm{N}$ e $362 \mathrm{~kg} \mathrm{ha}^{-1}$ de $\mathrm{K}_{2} \mathrm{O}$, com ganhos da ordem de $79,21 \%$ em relação aos efeitos analisados isoladamente.

Aos 240 DAT, a altura máxima foi de $187 \mathrm{~cm} \mathrm{na}$ combinação de $632,4 \mathrm{~kg} \mathrm{ha}^{-1}$ de $\mathrm{N}$ e $840 \mathrm{~kg} \mathrm{ha}^{-1}$ de $\mathrm{K}_{2} \mathrm{O}$ (FIG 1b). Enquanto que no momento da colheita do cacho, a altura obtida foi de $209 \mathrm{~cm}$ nas dosagens estimadas de $850 \mathrm{~kg} \mathrm{ha}^{-1}$ de $\mathrm{N}$ e $952 \mathrm{~kg} \mathrm{ha}^{-1}$ de $\mathrm{K}_{2} \mathrm{O}$ (FIG. 1c).

Pode-se observar que aos 240 DAT, as plantas que receberam a fertirrigação conjuntamente de nitrogênio e potássio apresentaram acréscimos de $69,62 \%$ e no final do primeiro ciclo foram de $52,78 \%$, ambos relacionados àquelas que não receberam fertirrigação. Ao comparar os resultados obtidos neste trabalho com aqueles constatados por Teixeira (2000), verificou-se que esses autores reportaram efeito isolado do potássio sobre o comprimento do pseudocaule da cv. "Nanicão", obtendo-se o máximo em altura de $230 \mathrm{~cm}$ na dose $628 \mathrm{~kg} \mathrm{ha}^{-1}$ de $\mathrm{K}_{2}$ 0. Já Melo et al. (2006), trabalhando com a cv. "Grand Naine" denotaram efeito significativo da interação $\mathrm{N} \mathrm{x} \mathrm{K}$, verificando comprimento máximo do pseudocaule de $256 \mathrm{~cm}$ na combinação de $400 \mathrm{~kg} \mathrm{ha}^{-1} \mathrm{de}$ $\mathrm{N}$ e $600 \mathrm{~kg} \mathrm{ha}^{-1}$ de $\mathrm{K}_{2} \mathrm{O}$.

Analisando-se o comportamento da altura das plantas ao longo do primeiro ciclo (FIG 1d), foi possível estimar a taxa de crescimento relativo (TCR) como índice de eficiência na produção de fitomassa. A bananeira teve crescimento lento até aproximadamente 

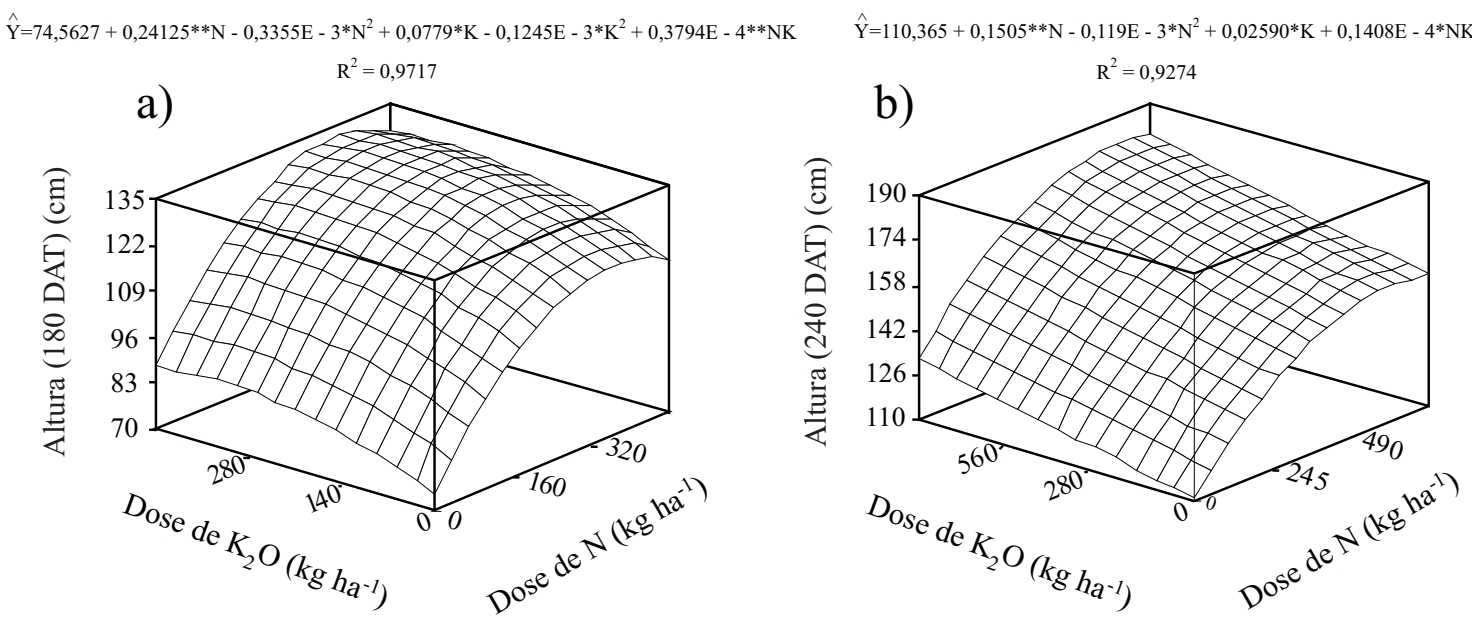

$\hat{\mathrm{Y}}=136,791+0,10193 * * \mathrm{~N}-5,345 \mathrm{E}-5^{*} \mathrm{~N}^{2}+0,0346 * \mathrm{~K}-2,0343 \mathrm{E}-5 * \mathrm{~K}^{2}+0,10367-4 * * \mathrm{NK}$
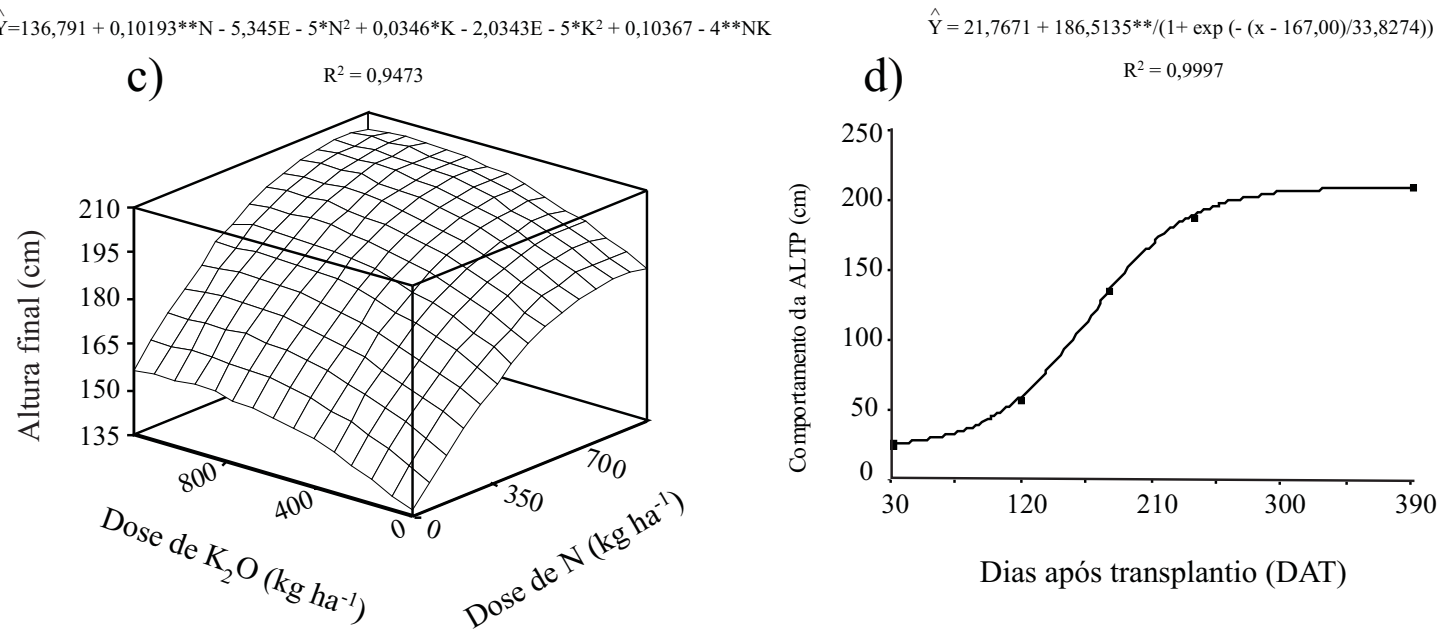

Figura 1 - Efeito combinado de nitrogênio e potássio, via fertirrigação, sobre a altura da planta (ALTP): aos seis meses (a), aos oito meses (b), no momento da colheita do cacho (c) e comportamento estimado da altura (d) da bananeira cv. Prata-Anã cultivada em solo de tabuleiros costeiros do estado de Sergipe

os 60 DAT $\left(0,06 \mathrm{~cm} \mathrm{~cm}^{-1} \mathrm{dia}^{-1}\right)$ devido às plantas gastarem grande parte da energia para fixação ao solo, notadamente, no período de adaptação da cultura no campo. Já aos 120 DAT, constatou-se uma taxa de $0,0162 \mathrm{~cm} \mathrm{~cm}^{-1} \mathrm{dia}^{-1}$, aos 180 DAT de $0,0144 \mathrm{~cm} \mathrm{~cm}^{-1} \mathrm{dia}^{-1}$. Aos 240 DAT a taxa de crescimento foi de $0,005 \mathrm{~cm} \mathrm{~cm}^{-1}$ $\mathrm{dia}^{-1}$, indicando que as plantas tiveram rápido crescimento a partir de 120 DAT até 240 DAT, mantendo pequeno acréscimo na TCR até a avaliação realizada aos 390 DAT $\left(0,0007 \mathrm{~cm} \mathrm{~cm}^{-1} \mathrm{dia}^{-1}\right)$. Neste estágio de crescimento, mais de $80 \%$ das parcelas tinham emitido os cachos, indicando a paralisação do ganho em altura. Deve-se salientar que aos 120 DAT, a bananeira tinha $27,63 \%$ da altura máxima estimada, aos 180 DAT 64\% e aos 240 DAT 89,56\%. Este comportamento se assemelha ao apresentado por Pereira et al. (2000) analisando a cv. "Prata-Anã" sob irrigação em diferentes espaçamentos no norte de Minas Gerais, ficando próximo ao relatado por Silva et al. (2003a) estudando vários genótipos em diferentes ambientes.

Quanto ao diâmetro do pseudocaule (DPC), verificouse efeito significativo da interação $\mathrm{N} \mathrm{x} \mathrm{K}(\mathrm{p}<0,01)$ a qual, foi desdobrada para verificar o efeito da fertirrigação nitrogenada dentro das doses de potássio, aos 120 DAT. Na dose zero de $\mathrm{K}_{2} \mathrm{O}$, o diâmetro máximo do pseudocaule foi de $6,47 \mathrm{~cm}$ alcançado na dose de $172,79 \mathrm{~kg} \mathrm{ha}^{-1}$ de N (FIG. 2a). Na dose $60 \mathrm{~kg} \mathrm{ha}^{-1}$ de $\mathrm{K}_{2} \mathrm{O}$ e $70 \mathrm{~kg} \mathrm{ha}^{-1}$ de N, o DPC máximo foi de $6,59 \mathrm{~cm}$, mantendo-se praticamente constante nas demais doses de N (FIG. 2b). Na presença de potássio (60 kg ha ${ }^{-1}$ de $\mathrm{K}_{2} \mathrm{O}$ ), a planta precisou de muito menos $\mathrm{N}$ para atingir um DPC ainda maior que aquele obtido na dose zero de K. Nas doses de 120 e $180 \mathrm{~kg} \mathrm{ha}^{-1}$ de $\mathrm{K}_{2} \mathrm{O}$, foi observada diminuição do DPC com o aumento das doses de $\mathrm{N}$, 

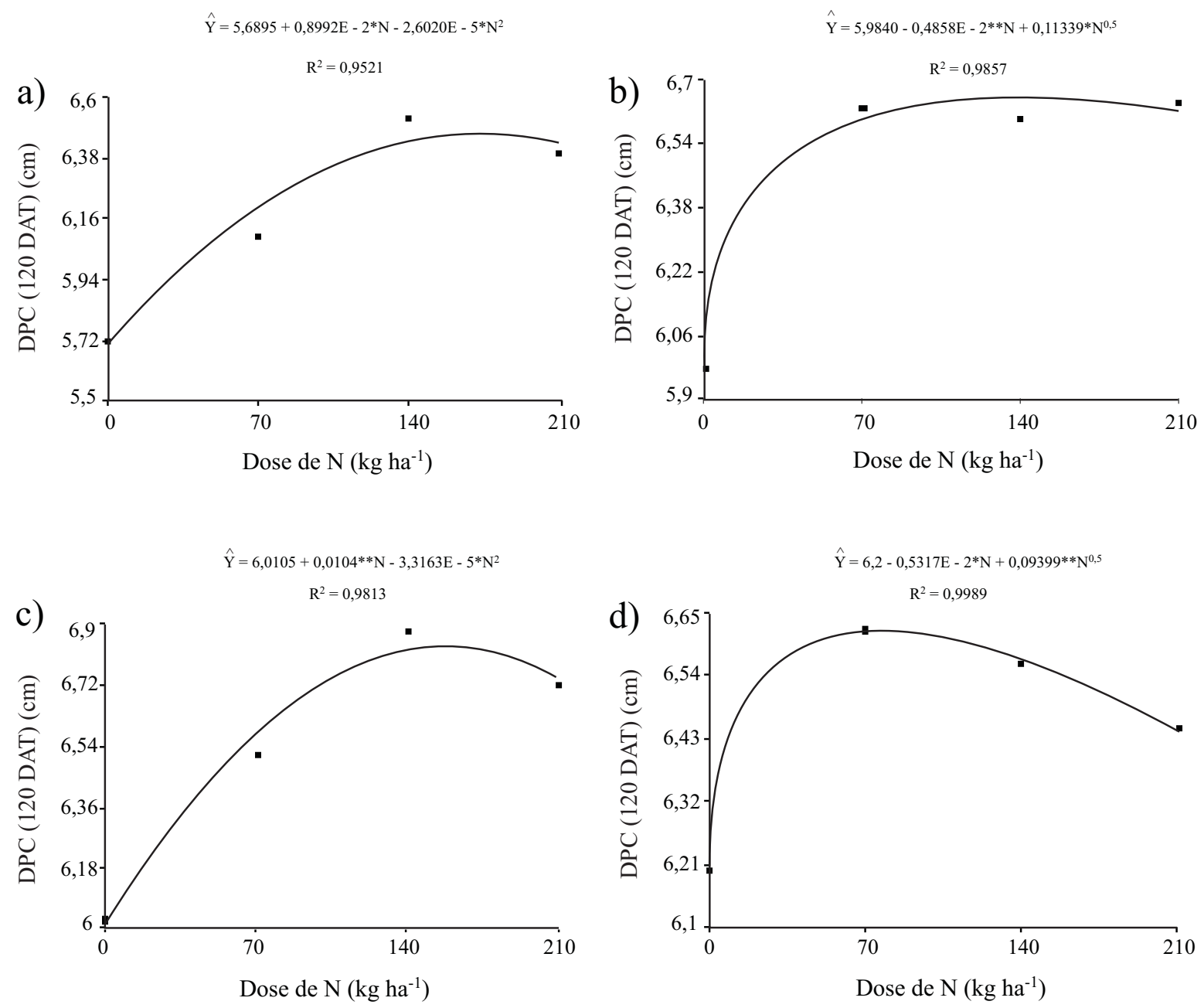

Figura 2 - Efeito de nitrogênio dentro das doses de potássio (0 (a); 60 (b); 120 (c) e 180 (d) kg ha he $^{-1}$, via fertirrigação, sobre o diâmetro do pseudocaule (DPC) aos quatro meses após o transplantio da bananeira cv. Prata-Anã sob fertirrigação em solo de tabuleiros costeiros do estado de Sergipe

principalmente na dose mais alta de K (FIG. 2c e 2d). Silva et al. (2003a) ressaltam que a mensuração do diâmetro do pseudocaule é importante no manejo do bananal, pois está relacionado ao vigor, refletindo na capacidade da planta em sustentar o cacho.

Aos 180 DAT (FIG. 3a), verificou-se que as plantas cresceram linearmente com o aumento da doses de potássio e de forma quadrática em função do nitrogênio. O diâmetro do pseudocaule máximo estimado (DPC) foi de $11,77 \mathrm{~cm}$ quando fertirrigado com $333,4 \mathrm{~kg} \mathrm{ha}^{-1}$ de $\mathrm{N}$ e $420 \mathrm{~kg} \mathrm{ha}^{-1}$ de $\mathrm{K}_{2} \mathrm{O}$, proporcionando um incremento no DPC de 46,11\% em relação às parcelas sem fertirrigação.

Aos 240 DAT (FIG. 3b), o DPC máximo estimado foi de 17,5 cm obtido na combinação de $707 \mathrm{~kg} \mathrm{ha}^{-1} \mathrm{de} \mathrm{N} \mathrm{e}$ $750 \mathrm{~kg} \mathrm{ha}^{-1}$ de $\mathrm{K}_{2} \mathrm{O}$; enquanto na última avaliação (FIG. 3c), o valor obtido foi de $21,78 \mathrm{~cm}$ na fertirrigação com $998 \mathrm{~kg} \mathrm{ha}^{-1}$ de $\mathrm{K}_{2} \mathrm{O}$ e $836 \mathrm{~kg} \mathrm{ha}^{-1}$ de N. Comparando-se os resultados de crescimento dessas avaliações, as plantas aos 240 DAT já tinham atingido cerca de $80,35 \%$ do seu diâmetro máximo (FIG. 3d).

Alguns resultados do efeito de $\mathrm{N}$ e $\mathrm{K}$ sobre variável DPC da bananeira apresentados na literatura são contraditórios. Respostas positivas à interação $\mathrm{N} \mathrm{x}$ $\mathrm{K}$ foram comentadas por (MELO et al., 2006), em que o DPC máximo de $20 \mathrm{~cm}$ foi atingido na combinação de $400 \mathrm{~kg} \mathrm{ha}^{-1}$ de $\mathrm{N}$ e $600 \mathrm{~kg} \mathrm{ha}^{-1}$ de $\mathrm{K}_{2} \mathrm{O}$. Por outro lado, Teixeira (2000) observou declínio linear em função do aumento de $\mathrm{N}$ e quadrático das doses de $\mathrm{K}$ sobre DPC. Essas discrepâncias podem ser atribuídas às condições edafoclimáticas ou manejo cultural, afetando a disponibilidade de nutrientes às plantas.

A área foliar (AF) máxima estimada aos 180 DAT foi de 4,94 $\mathrm{m}^{2}$ planta $^{-1}$ quando aplicados, via água de irrigação, 

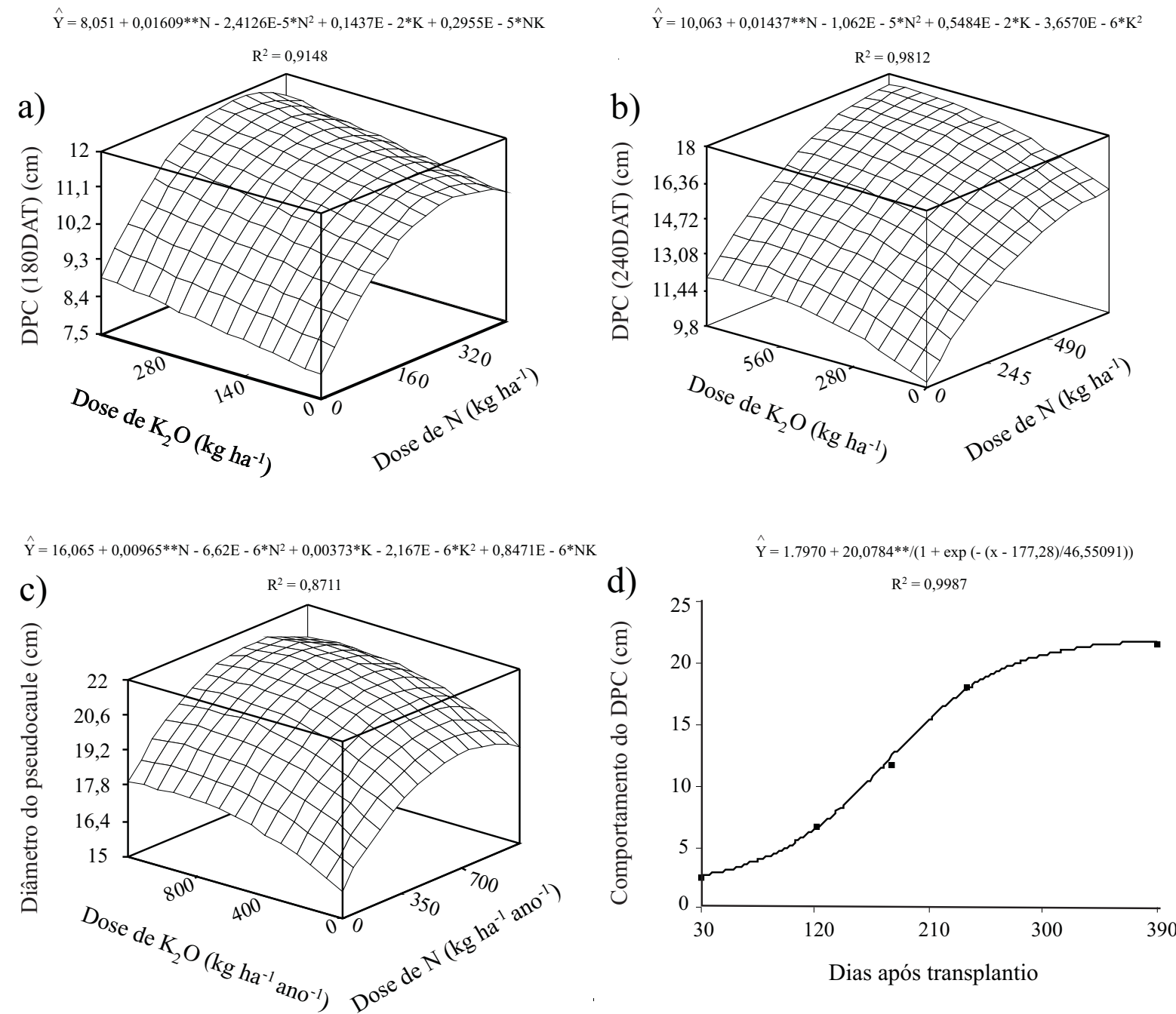

Figura 3 - Efeito combinado de nitrogênio e potássio, via fertirrigação, sobre o diâmetro do pseudocaule (DPC): aos seis meses (a), aos oito meses (b), no momento da colheita do cacho (c) e comportamento estimado do diâmetro do pseudocaule (d) da bananeira cv. Prata-Anã cultivada em solo de tabuleiros costeiros do estado de Sergipe

$360 \mathrm{~kg} \mathrm{ha}^{-1}$ de $\mathrm{N}$ e $420 \mathrm{~kg} \mathrm{ha}^{-1}$ de $\mathrm{K}_{2} \mathrm{O}$ (FIG. 4a). Analisando a superfície de resposta $\left(\mathrm{R}^{2}=0,92 * *\right)$, constata-se que houve acréscimo na $\mathrm{AF}$ de $158,64 \%$ em relação às parcelas que não receberam $\mathrm{N}$ e $\mathrm{K}$, de maneira muito expressiva. A Figura $4 \mathrm{~b}$ ilustra a tendência das plantas aos 240 DAT, onde se estimou que a AF máxima foi de $12,5 \mathrm{~m}^{2}$ planta $^{-1}$ na combinação de $592,47 \mathrm{~kg} \mathrm{ha}^{-1}$ de $\mathrm{N}$ e $840 \mathrm{~kg} \mathrm{ha}^{-1}$ de $\mathrm{K}_{2} \mathrm{O}$. Constatou-se variação positiva quando comparada ao período anterior (180 DAT) de $153 \%$, correspondendo à eficiência da fertirrigação de $23,19 \mathrm{~m}^{2} \mathrm{~kg}^{-1}$ de fertilizantes. Porém na avaliação realizada na época da colheita do cacho (FIG. 4c), ocorreram decréscimos de $26,4 \%$ da AFFinal $\left(9,2 \mathrm{~m}^{2}\right.$ planta $\left.^{-1}\right)$ em relação ao período de 240 DAT; sendo o índice de durabilidade foliar de $73,6 \%$. Na bananeira essa redução é normal (PEREIRA et al., 2000; SILVA et al., 2003b), porque a planta deixa de emitir novas folhas após a emissão da inflorescência e em virtude do desenvolvimento do cacho há translocação das reservas acumuladas nas folhas para os frutos. Isso acelera a senescência das folhas, com conseqüente diminuição da área foliar das plantas. No presente trabalho, se observou que as folhas mais velhas das plantas senesceram mais cedo, principalmente nos tratamentos sem de N e K. Para Teixeira (2000), a durabilidade foliar da bananeira "Nanicão" foi maior com o aumento da relação $\mathrm{K} / \mathrm{N}$ nas folhas.

Tanto o nitrogênio quanto o potássio promoveram aumentos significativos de natureza quadrática sobre ao fitomassa seca foliar(FMSF) (FIG. 5a). A produção máxima da FMSF estimada foi de 1528,4 g planta $^{-1}$ quando aplicados conjuntamente $441,35 \mathrm{~kg} \mathrm{ha}^{-1}$ de N e 755,2 $\mathrm{kg} \mathrm{ha}^{-1}$ de $\mathrm{K}_{2} \mathrm{O}$. $\mathrm{O}$ potássio foi bastante expressivo sobre o rendimento da 

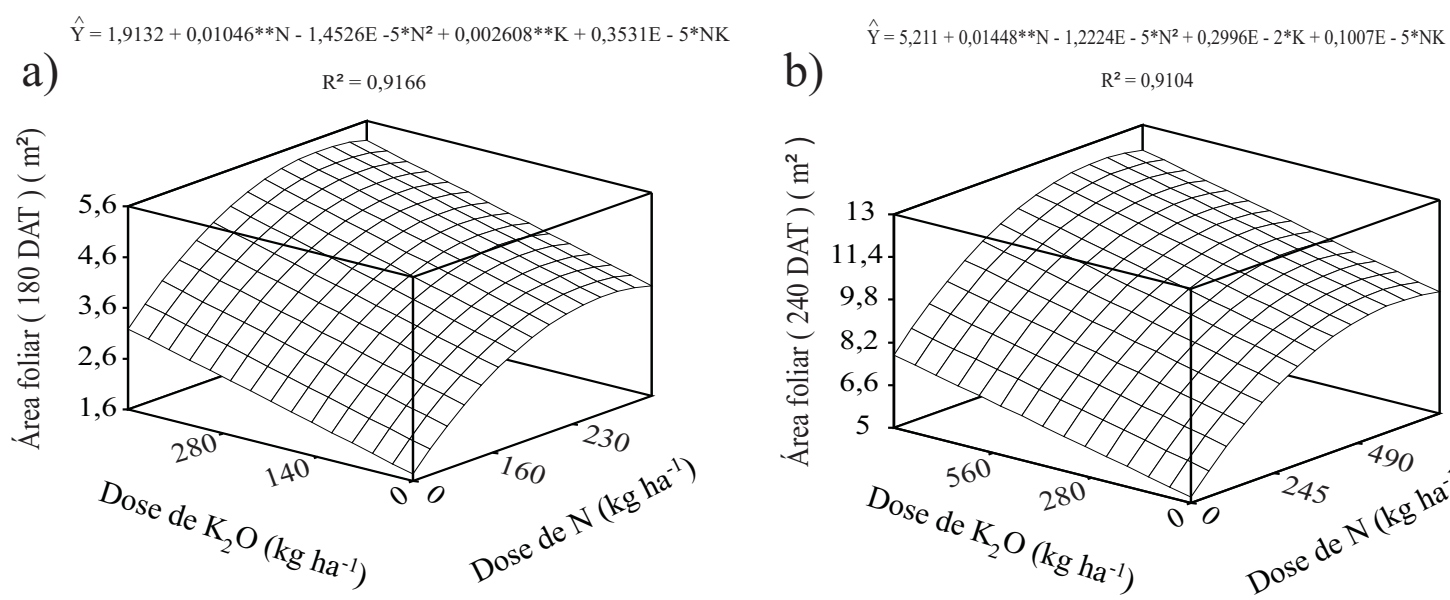

$\hat{\mathrm{Y}}=3,6+0,6721 \mathrm{E}-2 * \mathrm{~N}-3,6811 \mathrm{E}-6 \mathrm{~N}^{2}+0,48987 \mathrm{E}-2 * \mathrm{~K}-2,13 \mathrm{E}-6 * \mathrm{~K}^{2}+0,94 \mathrm{E}-6 * \mathrm{NK}$

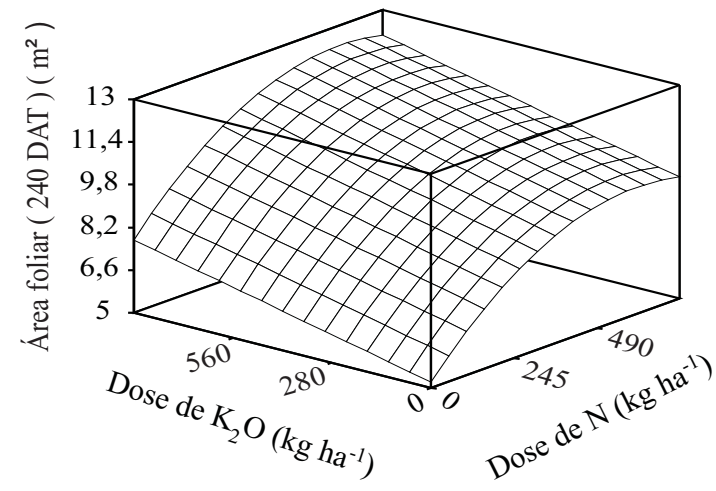

c) $\mathrm{R}^{2}=0,8499$

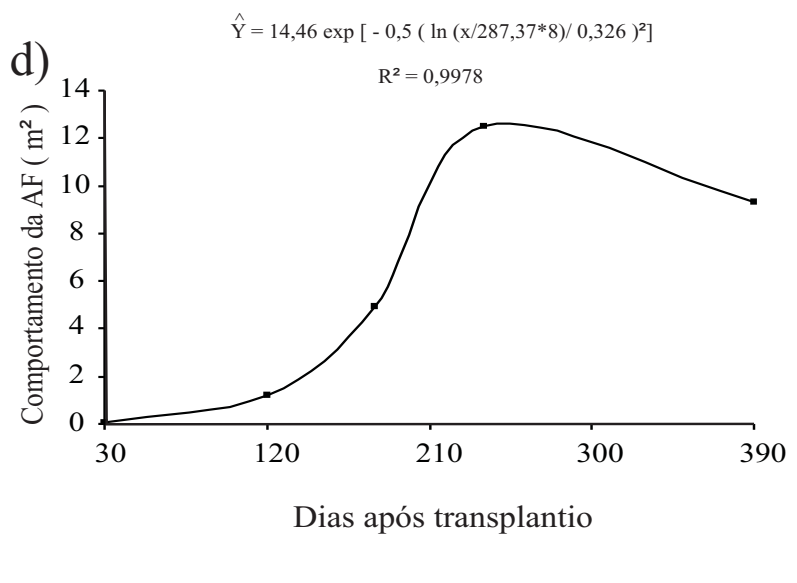

Figura 4 - Efeito combinado de nitrogênio e potássio, via fertirrigação, sobre a área foliar (AF): aos seis meses (a), aos oito meses (b), no momento da colheita do cacho (c) e comportamento estimado da área foliar (d) da bananeira cv. Prata-Anã cultivada em solo de tabuleiros costeiros do estado de Sergipe

FMSF (47,69\%), evidenciando a sua importância sobre o aumento e a preservação da área foliar da bananeira (SHABALA, 2003; TEIXEIRA, 2000).

Quanto à fitomassa seca do peseudocaule (FMSPC) (FIG. 5b), o maior valor (3545,95 g planta $^{-1}$ ) foi obtido, por meio do modelo de regressão $\left(\mathrm{R}^{2}=0,61^{* *}\right)$, quando foram aplicados $600 \mathrm{~kg} \mathrm{ha}^{-1} \mathrm{deNe} 1200 \mathrm{~kg} \mathrm{ha}^{-1} \mathrm{de} \mathrm{K}_{2} \mathrm{O}$. Na ausência da fertirrigação, o valor obtido foi de 2305,71 $\mathrm{g} \mathrm{planta}^{-1}$, resultando em decréscimo de 53,78\%. Para Alves et al. (2005), a bananeira Prata-Anã acumula, preferencialmente no início, maior fitomassa no pseudocaule e por final no cacho, indicando que os fotoassimilados produzidos pelas folhas são acumulados intermediariamente no pseudocaule, sendo depois translocados para o cacho.

No que se refere à fitomassa seca do cacho (FMSC), a maior produção obtida foi de 3412,52 g na combinação das maiores doses aplicadas de $\mathrm{N}$ e $\mathrm{K}$ (FIG. 5c). Estudando o efeito isolado de K, a FMSC obtida na dose de $1200 \mathrm{~kg} \mathrm{ha}^{-1} \mathrm{~K}_{2} \mathrm{O}$ foi equivalente a
$2771,92 \mathrm{~g}$, ao passo que o menor rendimento foi de $1562,08 \mathrm{~g}$, denotando ganho efetivo de 77,45\%. Já no efeito isolado de $\mathrm{N}\left(1050 \mathrm{~kg} \mathrm{ha}^{-1}\right.$ de $\left.\mathrm{N}\right)$, a FMSC foi de 2202,68 g e quando comparado à resposta das plantas que não foram fertirrigadas, registrou-se um incremento de $41 \%$. Enquanto que na aplicação conjunta de $1050 \mathrm{~kg} \mathrm{ha}^{-1}$ de $\mathrm{N}$ e $1200 \mathrm{~kg} \mathrm{ha}^{-1} \mathrm{~K}_{2} \mathrm{O}$, o ganho foi da ordem de $118,46 \%$. Isso indica uma grande sensibilidade da bananeira "Prata-Anã" à deficiência, em especial, ao potássio na produção dos frutos. Tais informações denotam que durante a produção da fitomassa seca do cacho, o potássio foi utilizado em maior quantidade que o nitrogênio. Neves et al. (1991), avaliando a nutrição mineral da bananeira, observaram ser o potássio o elemento mais exportado pelos frutos, aproximadamente $35 \%$ do total absorvido. Essa assertiva é reforçada por Pinto et al. (2005), que afirmaram que a bananeira necessita de $\mathrm{K}$ em quantidade superior ao $\mathrm{N}$ para se obter alto rendimento de cachos. 

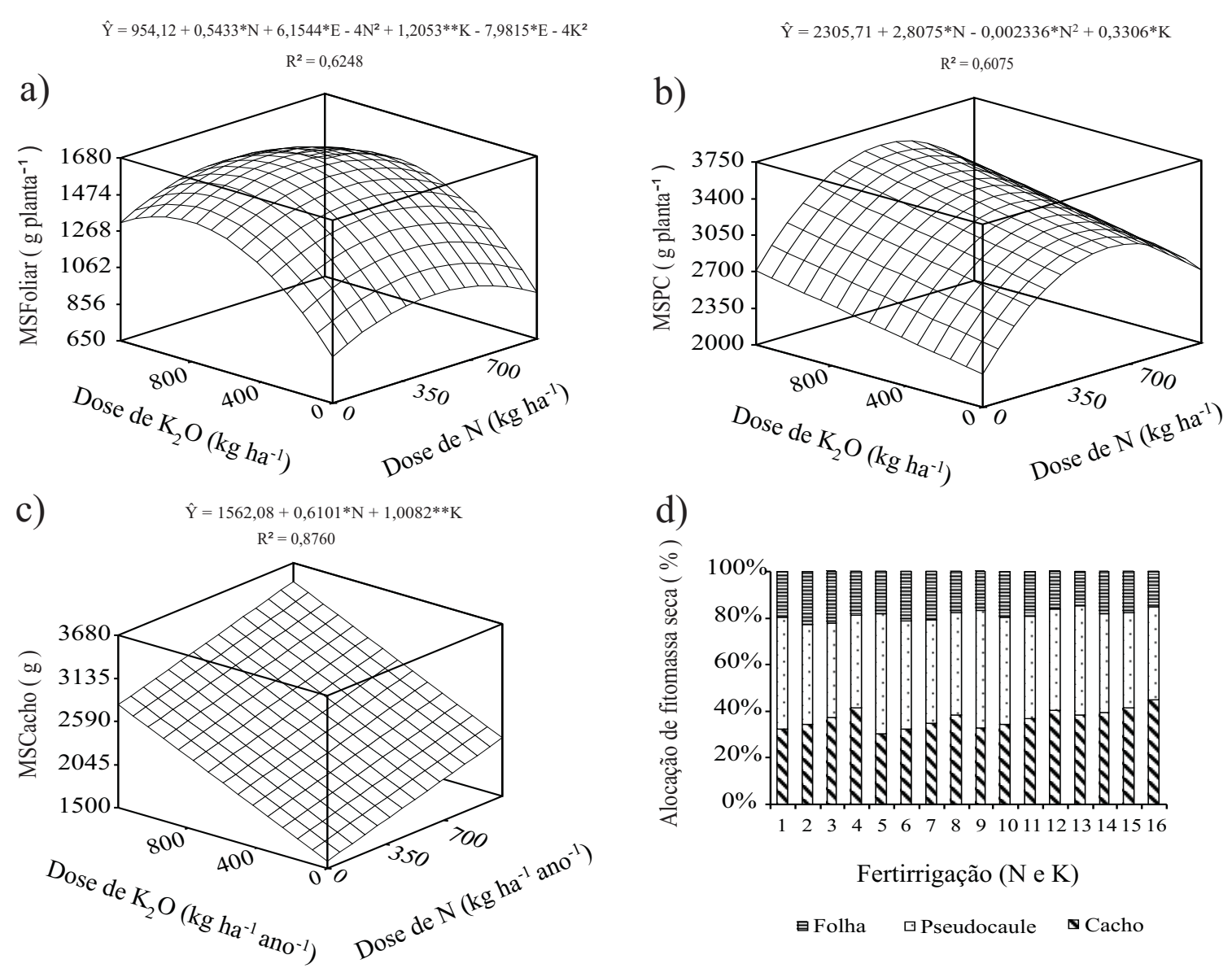

d)

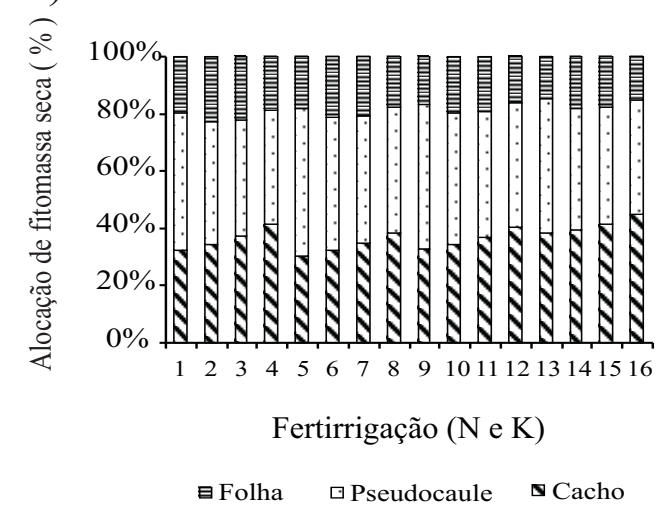

Figura 5 - Efeito combinado da adubação nitrogenada e potássica via fertirrigação sobre a FMSF (a), a FMSPC (b), a FMSC (c) e particionamento de fitomassa seca da parte aérea (d) da bananeira cv. Prata-Anã cultivada em solo de tabuleiros costeiros do estado de Sergipe. 1: (0;0), 2: (0;400), 3: (0:800), 4: (0:1200) 5: (350;0), 6: (350;400), 7: (350:800), 8: (350:1200), 9: (700;0), 10: (700;400), 11: (700:800), 12: (700:1200) 13: (1050;0), 14: (1050;400), 15: (1050:800), 16: (1050:1200), em kg ha-1 ano $^{-1}$

A partição de fitomassa seca da planta, entre limbos, bainhas foliares e cachos, foi influenciada pelos tratamentos estudados. A distribuição de fitomassa seca da parte aérea destinada à FMSF correspondeu a 16,51\%, à FMSPC a $43,77 \%$ e à FMSC a $39,71 \%$ do rendimento total máximo estimado de 8054,88 $\mathrm{g} \mathrm{planta}^{-1}$, que foi obtido na combinação de $700 \mathrm{~kg} \mathrm{ha}^{-1}$ de $\mathrm{N}$ e $1200 \mathrm{~kg} \mathrm{ha}^{-1}$ de $\mathrm{K}_{2} \mathrm{O}$ (FIG. 5d). Na ausência da fertilização com $\mathrm{N}$ e K, o rendimento da biomassa seca foi de 4821,91 $\mathrm{g} \mathrm{planta}^{-1}$, expressando $19,78 \%$ destinados às folhas, $47,82 \%$ ao pseudocaule e $34,47 \%$ ao cacho. A diferença observada na alocação da FMSF $(3,27 \%)$ pode ser explicada por serem as folhas estoques de fotoassimilados e na fase de envelhecimento ocorrem a retranslocação para os frutos (LARCHER, 2006), podendo ser evidenciado pela maior porcentagem da FMSC das parcelas fertirrigadas.

Uma dos componentes da razão da área foliar (RAF) é a área foliar específica (AFE) que representa o inverso da espessura das folhas, pois se trata de um indicativo que é traduzido pelas alterações no número ou tamanho das células do mesófilo foliar. Esta variável foi reduzida em $22,87 \%$ pela maior disponibilidade de nitrogênio (FIG. 6a), levando a evidenciar que bananeiras da cultivar "Prata-Anã", tendem expressar a folha-índice mais espessa. Isso ocorreu em decorrência de maior número de estratos celulares ou aumento dos espaços intercelulares, contudo em situação de deficiência de nitrogênio a divisão e a expansão das células diminuem, havendo redução no tamanho de todas as partes morfológicas da planta. No que concerne aos resultados encontrados da AFE, o incremento acentuado na fitomassa seca do limbo para esses tratamentos, é atribuído ao crescimento de folhas pré-existentes e não ao surgimento de novas folhas.

O aproveitamento da radiação fotossinteticamente ativa $(\xi)$ pelas plantas, ou seja, a eficiência em transformar energia solar em energia química (LARCHER, 2006) em função das doses de $\mathrm{N}$ e K é mostrada na (FIG. 6b). A $\xi$ máxima estimada de $2,68 \mathrm{~g} \mathrm{MJ}^{-1}$ foi verificada quando as plantas receberam conjuntamente $732 \mathrm{~kg} \mathrm{ha}^{-1}$ de $\mathrm{N}$ 


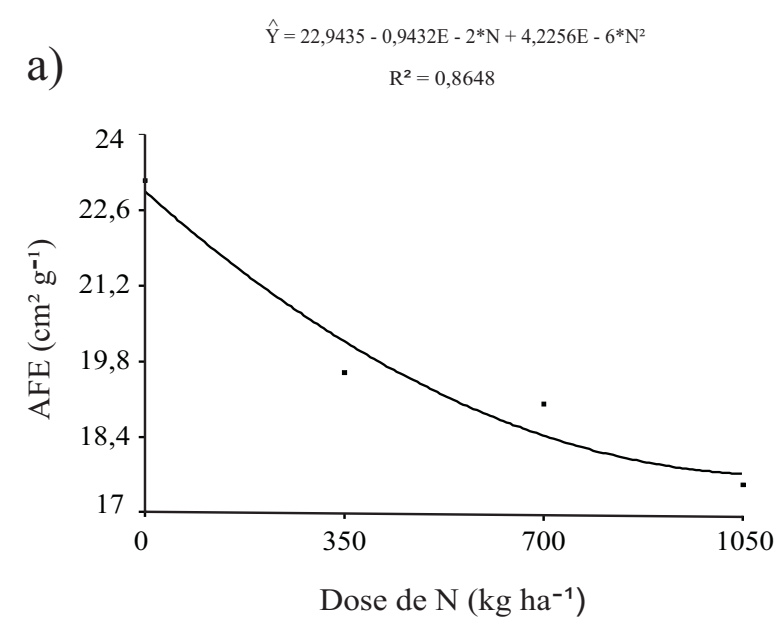

c)

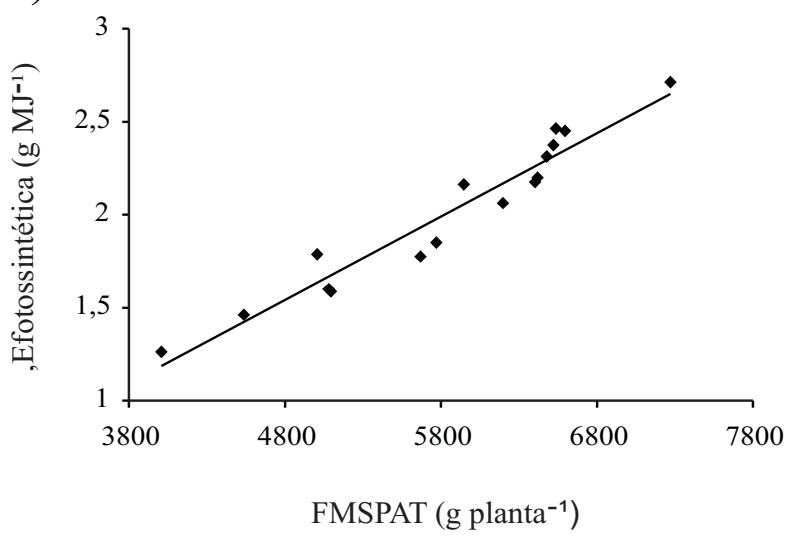

b)

$\hat{\mathrm{Y}}=1,2307+0,1273 \mathrm{E}-2 * \mathrm{~N}-8,6096 \mathrm{E}-7 * \mathrm{~N}^{2}+0,6061 \mathrm{E}-3 * \mathrm{~K}+0,281 \mathrm{E}-6 * \mathrm{NK}$

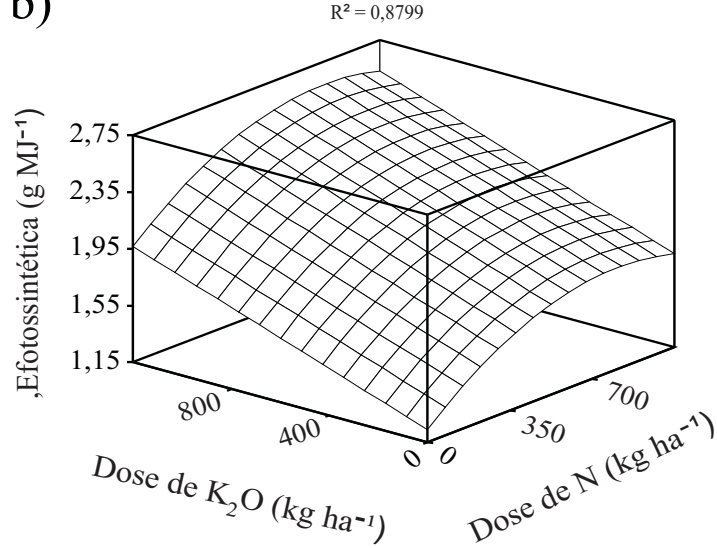

d)

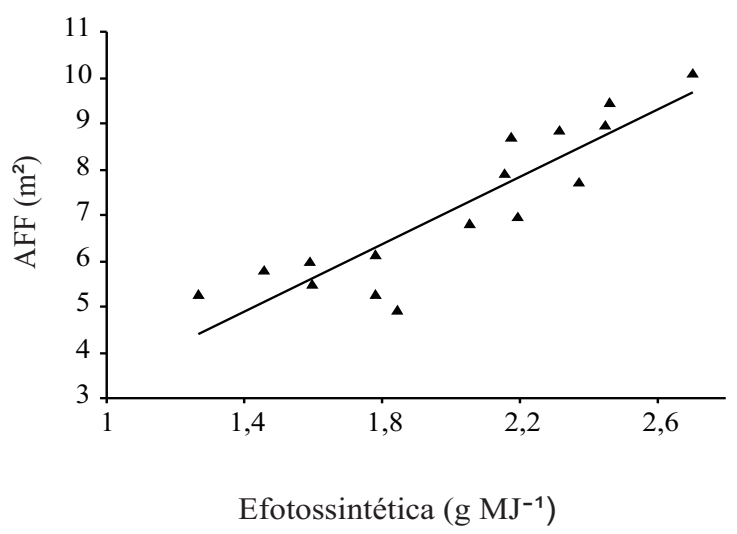

Figura 6 - Efeito de nitrogênio sobre a área foliar específica (AFE) (a), da combinação N x K na eficiência fotossintética ( $\xi$ ) (b), da correlação de Pearson entre a ( $\xi$ ) e FMSPAT (c) e entre a AFF e $\xi(d)$ da bananeira cv. Prata-Anã fertirrigada em solo de tabuleiros costeiros do estado de Sergipe

e $1200 \mathrm{~kg} \mathrm{ha}^{-1}$ de $\mathrm{K}_{2} 0$. Nota-se que houve um aumento de $117,87 \%$ quando comparado esse rendimento ao observado na testemunha de 1,23 $\mathrm{g} \mathrm{MJ}^{-1}$. Além disso, por meio das correlações entre a $\xi$ e a FMSPAT $(\mathrm{r}=0,97 * *)$ (FIG. 6c) e a AFF e $\xi\left(\mathrm{r}=0,89^{* *}\right.$ ) (FIG. 6d) evidenciamse que houve excelente conversão energética pela cultura da banana em condições adequadas, notadamente, de nitrogênio e potássio. Cayón Salinas (2001) mencionou que o rendimento da bananeira depende da eficiência na conversão da radiação solar interceptada em biomassa. Esse comportamento pode ser explicado pelo autosombreamento devido à maior área foliar, pois a eficiência de uso da radiação varia dentro de uma mesma espécie e que folhas saturadas por irradiação são menos eficientes do que as sombreadas (RADIN et al., 2003). Para os autores, a distribuição mais uniforme da irradiação solar através do dossel tende não saturar a maioria das folhas, justificando-se a resposta positiva na produção de fitomassa.

\section{Conclusões}

1- O maior ganho na produção de fitomassa seca da parte aérea $\left(8054,88 \mathrm{~g} \mathrm{planta}^{-1}\right)$ foi obtido na combinação de $700 \mathrm{~kg} \mathrm{ha}^{-1} \mathrm{ano}^{-1}$ de $\mathrm{N}$ e $1200 \mathrm{~kg} \mathrm{ha}^{-1} \mathrm{ano}^{-1}$ de $\mathrm{K}_{2} \mathrm{O}$;

2- Do total da fitomassa seca, 16,51\% foram destinados às folhas, 43,77\% ao pseudocaule e $39,71 \%$ ao cacho;

3- Doses elevadas de $\mathrm{N}$ e baixas de $\mathrm{K}$ causaram a ontogenia mais rápida das folhas, diminuíram a razão da área foliar e o rendimento da bananeira "Prata anã";

4- As altas doses de nitrogenio tornaram o mesófilo foliar mais espesso;

5- A maior conversão da irradiação solar em fitomassa seca pela bananeira correspondeu à combinação de $732 \mathrm{~kg} \mathrm{ha}^{-1}$ de $\mathrm{N}$ com $1200 \mathrm{~kg} \mathrm{ha}^{-1}$ de $\mathrm{K}_{2} \mathrm{O}$. 


\section{Agradecimentos}

Ao $\mathrm{CNPq}$ pela concessão da bolsa de doutorado ao primeiro autor, à FINEP pelo financiamento do projeto de pesquisa e a Boa Safra Fertilizantes S/A pela doação do cloreto de potássio.

\section{Referências}

ALLEN, R. G. et al. Crop evapotranspiration: guidelines for computing crop water requirements. Roma: FAO, 1998. 300 p. (Irrigation and Drainage Paper, 56)

ALVES, A. N. et al. Crescimento e desenvolvimento de duas variedades de bananeira irrigadas sob estresse salino. Revista Brasileira de Engenharia Agrícola e Ambiental, v. 40, n. 04, p. 379-389, 2005.

BORGES, A. L. et al. Adubação nitrogenada para bananeira "Terra" (Musa sp. AAB, subgrupo Terra). Revista Brasileira de Fruticultura, v. 24, n. 01, p.189-193, 2002.

BORGES, A. L. et al. Teores foliares de nutrientes em genótipos de bananeira. Revista Brasileira de Fruticultura, v. 28, n. 02, p. 314-318, 2006.

CAYÓN SALINAS, D. G. Evolución de la fotosíntesis, transpiración y clorofila durante el desarrollo de la hoja de plátano (Musa AAB Simmonds). InfoMusa, v. 10, n. 01, p. 12-15, 2001.

COELhO, E. F.; SOUSA, V. F. de; AGUiAR NETTO, A. de O. Manejo de irrigação em fruteiras tropicais. Cruz das Almas: Embrapa Mandioca e Fruticultura, 2000. 48 p. (Circular Técnica, 40).

DAMATTO JÚNIOR, E. R. et al. Avaliação nutricional em folhas de bananeira "Prata-Anã" adubada com composto orgânico. Revista Brasileira de Fruticultura, v. 28, n. 01, p. 109-112, 2006.

FOOD AND AGRICULTURE ORGANIZATION OF THE UNITED NATIONS (FAO). Faostat. Disponível em: $<$ http://www.fao.org/ag/guides/resource/data.htm>. Acesso em: junho de 2007.

FIGUEIREDO, F. P. et al. Influência da lâmina de irrigação sobre a eficiência energética, uso de água e produtividade da bananeira "Prata-Anã". Revista Brasileira de Agrometeorologia, v. 13, n. 01, p. $53-58,2005$

FONSECA, E. L.; SILVEIRA, V. C.; SALOMONI, E. Eficiência de conversão da radiação fotossinteticamente ativa incidente em biomassa aérea da vegetação campestre natural no bioma Campos Sulinos do Brasil. Ciência Rural, v. 36, n. 02 , p. $656-659,2006$

GUERRA, A. G. et al. Freqüência de fertirrigação da bananeira prata-anã com nitrogênio e potássio aplicados por microaspersão. Engenharia Agrícola, v. 24, n. 01, p. 80-88, 2004.

LARCHER, W. Ecofisiologia vegetal. São Carlos: RIMa Artes e Textos, 2006. 532 p.
MAHALAKSHMI, M.; KUMAR, N.; SOORIANATHASUNDARAM, K. Effect of fertirrigation and irrigation on the yield of hight-density plantations of cv. "Robusta". InfoMusa, v. 12, n. 01, p. 42-44, 2003.

MELO, F. B. et al. Crescimento e produção de frutos de bananeira cultivar "Grand Naine" relacionados à adubação química. Revista Ciência Agronômica, v. 37, n. 02, p. 246-249, 2006.

MOREIRA, R. S. Banana: teoria e prática de cultivo. São Paulo: Fundação Cargill. 1999. 1 CD-ROM.

NEVES, R. L. L. et al. Extração de nutrientes em banana (Musa spp.) cv. Pacovan. Revista Ciência Agronômica, v. 22, n. 02, p.115-120, 1991

PEREIRA, M. C. T. et al. Crescimento e produção do primeiro ciclo da bananeira Prata-Anã (AAB) em sete espaçamentos. Pesquisa Agropecuária Brasileira, v. 35, n. 07, p. 1377-1387, 2000.

PEREIRA, A. R.; ANGELOCCI, L. R.; SENTELHAS, P. C. Agrometeorologia: fundamentos e aplicações. São Paulo: Funep. 2002, 478 p.

PINTO, J. M. et al. Doses de nitrogênio e potássio aplicadas via fertirrigação em bananeira. Irriga, v. 10, n. 01, p. 46-52, 2005.

RAIJ, B. Van. et al. Recomendação de adubação e calagem para o Estado de São Paulo. 2. ed. Campinas: IAC, 1996. 285 p. (Boletim Técnico, 100).

RANDIN, B. et al. Eficiência no uso da radiação fotossinteticamente ativa pela cultura do tomateiro em diferentes ambientes. Pesquisa Agropecuária Brasileira, v. 38, n. 9, p. 1017-1023, 2003

ROMERO, J. O.; ZAMORA, O. P. Tensión de humedad del suelo y fertilización nitrogenada en plátano (Musa AAA Simmonds) cv. Gran Enano. Agrociencia, v. 40, n. 02, p. 149-162, 2006.

SANTOS, H. G. et al. Sistema brasileiro de classificação de solos. 2 ed. Rio de Janeiro: Embrapa Solos, 2006. 306 p.

SHABALA, S. Regulation of potassium transport in leaves from molecular to tissue level. Annals of Botany, v. 92, n. 05, p. 627-634, 2003.

SHIMAZAKI, K. I. et al. Light regulation of stomatal movement. Annual Review of Plant Biology, v. 58, p. 219-247, 2007.

SILVA, S. O. et al. Avaliação de genótipos de bananeira em diferentes ambientes. Revista Ciência e Agrotecnologia, v. 27, n. 04 , p. $737-748,2003 a$.

SILVA, J. T. A. et al. Adubação com potássio e nitrogênio em três ciclos de produção da bananeira cv. Prata-Anã. Revista Brasileira de Fruticultura, v. 25, n. 01, p. 152-155, 2003 b.

TEIXEIRA, L. A. J. Aduabação nitrogenada e potássica em bananeira "Nanicão" (Musa AAA subgrupo Cavendish) sob duas condições de irrigação. Jaboticabal, 2000. $132 \mathrm{f}$. Tese (Doutorado em Agronomia) - Faculdade de Ciências Agrárias e Veterinárias, Universidade Estadual Paulista, Jaboticabal. 